\title{
Indikasi Potensi Gas Hidrat Sebagai Sumber Energi Nonkonvensional di Wilayah Maritim Indonesia
}

\author{
Hendry Wirandoko, Dirga Wahyuzar, Boi Haris H. Siahaan \\ Program Studi Teknik Geologi, Fakultas Teknologi Mineral, Universitas Pembangunan Nasional "Veteran" \\ Yogyakarta, Yogyakarta 55283, Indonesia \\ Correspondence: wirandokohendry18@gmail.com
}

Received: 21 May 2021; Accepted: 30 May 2021; Published: 20 June 2021

\begin{abstract}
Abstrak: Gas hidrat merupakan sumber energi nonkonvesional yang kuantitasnya hampir dua kali lebih banyak apabila dibandingkan dengan energi yang bersumber dari fosil. Oleh karena itu, penulis memiliki tujuan untuk mengembangkan potensi gas hidrat tersebut dan mengindikasikan potensi persebaran serta pembentukannya di Indonesia. Metode penelitian yang digunakan yaitu studi pustaka yang bersumber dari literatur seperti jurnal, artikel, dan buku. Berdasarkan penelitian ini, potensi cadangan gas hidrat di Indonesia dapat ditemukan di wilayah perairan Indonesia terutama perairan laut dalam seperti di Cekungan Busur Muka Simeulue, Sumatera dan Selat Makassar. Selain itu, potensi tersebut juga didukung oleh adanya kegiatan tektonik yang terjadi Indonesia. Metode geofisika seismik, BSR (Bottom Stimulating Reflector) dan analisa AVO merupakan beberapa metode yang digunakan untuk mengindikasikan adanya keberadaan potensi gas hidrat di suatu daerah. Gas hidrat dapat menjadi substitusi bagi bahan bakar fosil dan berpotensi masuk tahap eksplorasi dan eksploitasi, sehingga dibutuhkan studi lanjutan agar dapat diproduksi secara komersial.
\end{abstract}

Kata Kunci: bottom stimulating reflector (BSR), gas hidrat, Indonesia, laut dalam, seismik

\begin{abstract}
Gas hydrate is a non-conventional energy source, which is almost twice as large as fossil energy sources. Therefore, the authors want to develop gas hydrate potential and indicate the potential for its distribution and formation in Indonesia. The research method used is literature study sourced from literature such as journals, articles and books. Based on this research, the potential gas hydrate reserves in Indonesia is found in Indonesian territorial waters, especially deep sea waters such as the Simeulue Forearc Basin, Sumatra and the Makassar Strait. In addition, this potential is supported by tectonic activity occurs in Indonesia. Seismic geophysical methods, BSR (Bottom Stimulating Reflector) and AVO analysis are some of the methods used to indicate presence gas hydrate potential in area. Gas hydrate can be substitute fossil fuels and has the potential enter the exploration and exploitation stage, so further studies needed so that it can be produced commercially.
\end{abstract}

Keywords: bottom stimulating reflector (BSR), deep sea, gas hydrate, Indonesia, seismic

\section{PENDAHULUAN}

Sumber energi yang digunakan saat ini sebagian besar masih berasal dari sumber energi fosil seperti batubara, minyak bumi, dan gas alam yang dalam pembentukannya membutuhkan waktu hingga jutaan tahun. Saat ini permintaaan terhadap bahan bakar fosil khususnya minyak bumi semakin tinggi, sehingga cadangannya diperkirakan menipis untuk belasan tahun ke depan (Skkmigas, 2020). Oleh karena itu, upaya untuk mencari keberadaan sumber energi baru sebagai substitusi bahan bakar fosil terus dilakukan, salah satu sumber 
energi tersebut adalah gas hidrat yang ramah lingkungan untuk menekan terjadinya pemanasan global (Kvenvolden, 1998).

Indonesia sebagai sebuah negara maritim memiliki wilayah lautan yang luas, sehingga sangat berpotensi untuk memiliki sumberdaya alam nonkonvensional berupa gas hidrat dalam jumlah yang sangat besar. Cadangan gas hidrat yang terdapat Indonesia tersebar dari lautan barat Indonesia sampai timur Indonesia, antara lain terdapat di bagian barat Sumatera Utara, Selat Sunda, Selat Makassar, perairan dibagian utara Manado, serta di perairan Maluku dan Papua. Banyaknya sumber cadangan gas hidrat yang tersebar di berbagai wilayah di Indonesia tersebut, sehingga diperkirakan bahwa Indonesia memiliki total cadangan sebesar 3.000 TCF (Tiga Ribu Milyar Kaki Kubik). Selain itu, gas hidrat memiliki cadangan sebesar 1015-1017 $\mathrm{m}^{3}$ yang sebanding dengan dua kali lipat cadangan gas konvensional $\left(2,5 \times 1014 \mathrm{~m}^{3}\right)$ dan hampir dua kali lipat lebih besar jika dibandingkan dengan sumber energi yang berasal dari fosil seperti batubara, minyak bumi, dan gas alam (Kvenvolden, 1988) yang ditunjukkan pada Gambar 1.

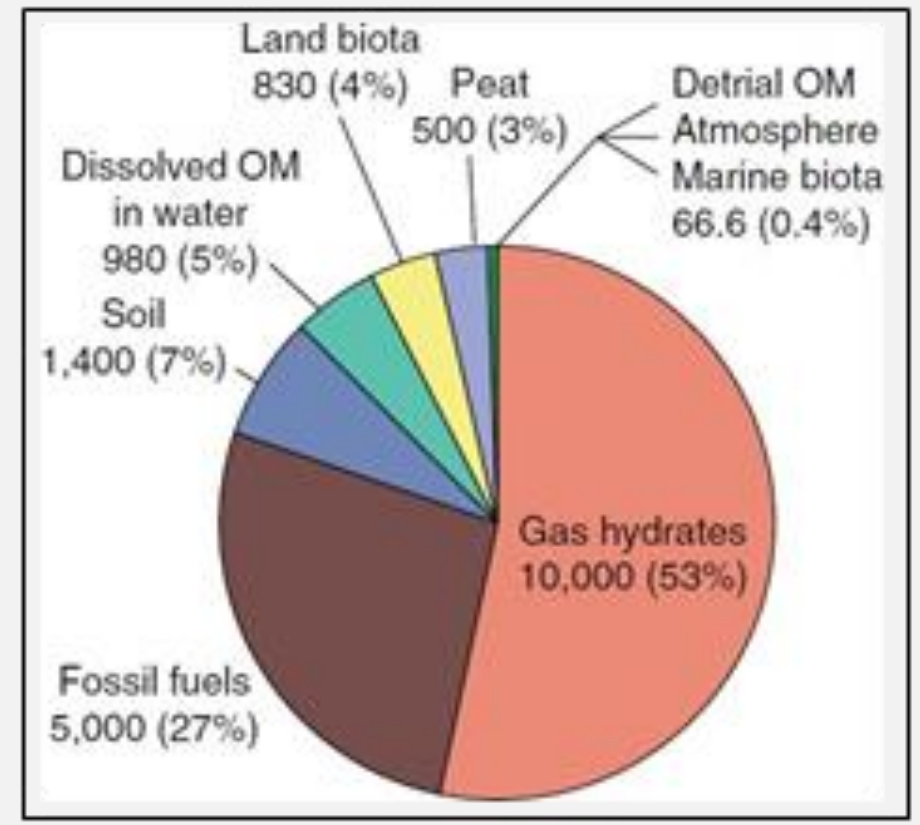

Gambar 1. Distribusi organik karbon di dunia dengan estimasi gas hidrat sebagai yang terbesar dan dua kali lebih besar dari energi konvensional (Sumber: Kvenvolden, 1998).

Gas hidrat (methane hydrate) merupakan suatu material padat yang terbentuk oleh molekul $\mathrm{CH}_{4}$ dari susunan molekul air dan gas yang terperangkap di dalam struktur kristal hidrat (cathrate) (Dagar \& Joshi, 2013). Methane hydrate berbentuk padat dan terbentuk oleh molekul $\mathrm{CH}_{4}$ yang dikelilingi oleh 20 molekul air sebagai pengikatnya (Dagar \& Joshi, 2013). Morfologi yang terbentuk dari kristal sangat beragam, hal ini disebabkan oleh faktor komposisi dan kondisi pertumbuhan kristal (Makogon et al., 2007). Pembentukan yang relatif singkat dari gas hidrat adalah salah satu aspek yang menarik jika dibandingkan dengan minyak bumi, hal ini diakibatkan oleh faktor sumber gas yang berasal dari gas biogenik. Selain itu, faktor menarik lainnya adalah keterdapatan gas hidrat yang masif diseluruh belahan dunia (Gambar 2), kemudian pengembangan volume metana yang dihasilkan di permukaan, dapat lebih besar hingga 164 kali lipat dibandingkan metana in situ gas hidrat (Max \& Johnson, 2016). 


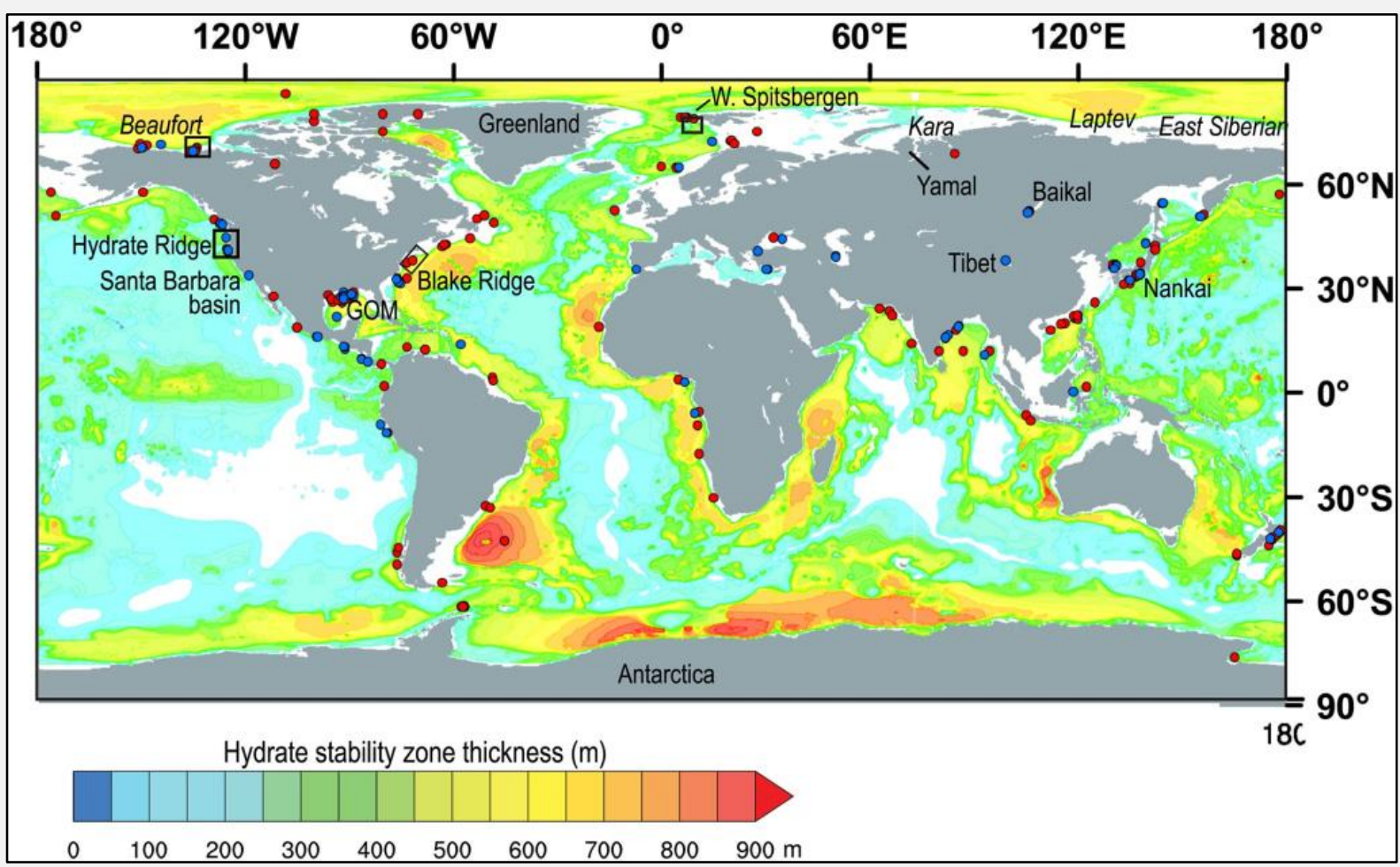

Gambar 2. Zona stabilitas gas hidrat di seluruh dunia (Sumber: Ruppel \& Kessler, 2017)

Namun, sebagai harapan sumber energi hidrokarbon nonkonvesional di masa yang akan datang dengan berbagai keunikan, kelebihannya dan kelimpahannya, teknologi untuk produksi gas hidrat masih belum dapat dilaksanakan secara komersial sehingga gas hidrat ini belum bisa dimanfaatkan dalam skala yang besar. Oleh karena itu, studi gas hidrat melalui aspek geologi dan geofisika sudah harus dimulai, agar Indonesia mampu mengikuti pengembangan sumber energi dan teknologi di masa yang akan datang. Pada kegiatan eksplorasi gas hidrat, konsep-konsep eksplorasi secara umum mirip dengan hidrokarbon konvensional, namun beberapa indikator terutama dalam geofisika cukup berbeda. Berdasarkan permasalahan tersebut, maka terbentuklah gagasan untuk melakukan penelitian yang membahas tentang potensi sumber daya gas hidrat di Indonesia agar dapat dimanfaatkan di masa depan sebagai pengganti sumber daya konvensional. Adapun tujuan dilakukannya penelitian mengenai potensi gas hidrat ini adalah untuk melakukan identifikasi keterdapatan gas hidrat di wilayah maritim Indonesia dengan menggunakan metode geofisika dan juga memperhatikan aspek geologi daerah tersebut.

\section{METODE PENELITIAN}

Penelitian dilakukan dengan berfokus pada beberapa contoh lokasi yaitu Selat Makassar (Gambar 3) dan perairan barat Sumatera (Aceh) yang dari tatanan geologinya menempati Cekungan Busur Muka Simeulue (Gambar 4). Penelitian dilakukan melalui pendekatan studi pustaka dengan bersumber pada jurnal ilmiah, artikel, buku dan penelitian terdahulu seputar data penelitian indikasi gas hidrat di Indonesia, sehingga dapat digunakan sebagai acuan dan dasar teori dalam pelaksanaan penelitian ini nantinya. Studi Pustaka merupakan hal yang harus dilakukan agar informasi yang disampaikan lebih lengkap dan data yang akan diperoleh di lapangan akan jauh lebih detail. 


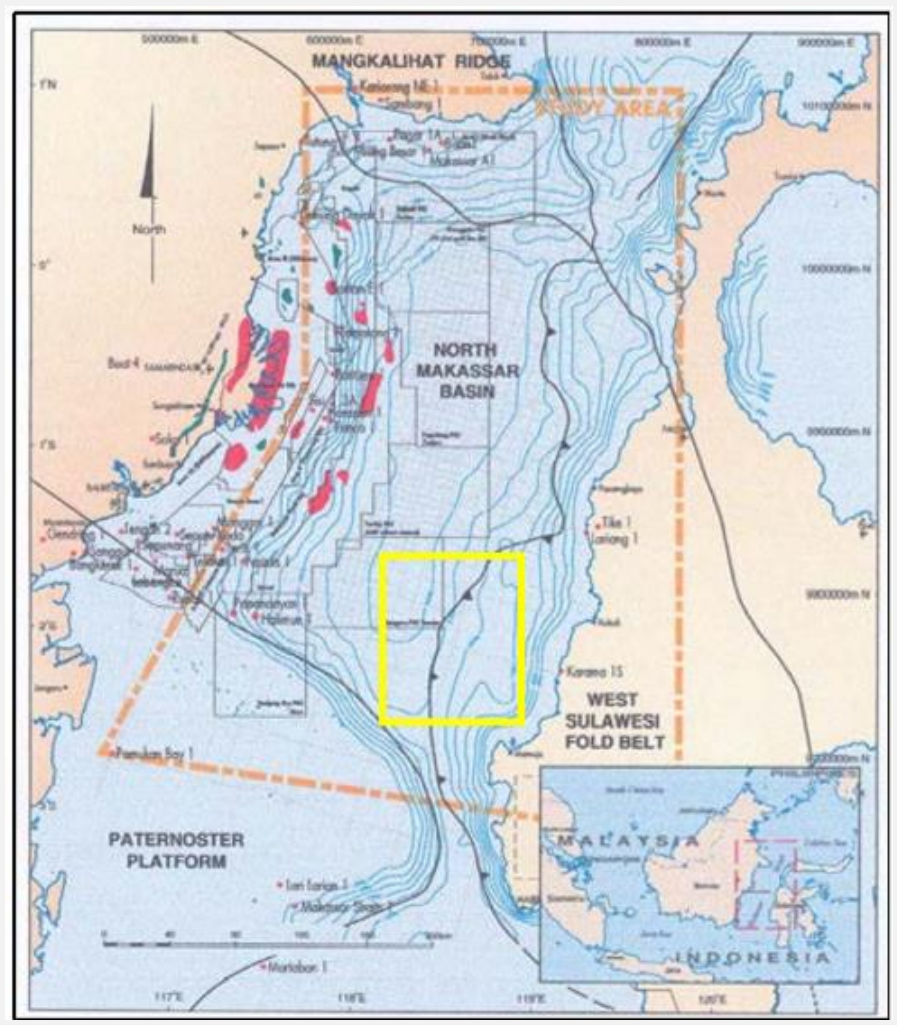

Gambar 3. Wilayah lapangan hidrokarbon di Selat Makassar, kotak kuning merupakan perkiraan daerah penelitian (Sumber: Fraser et al., 2003)

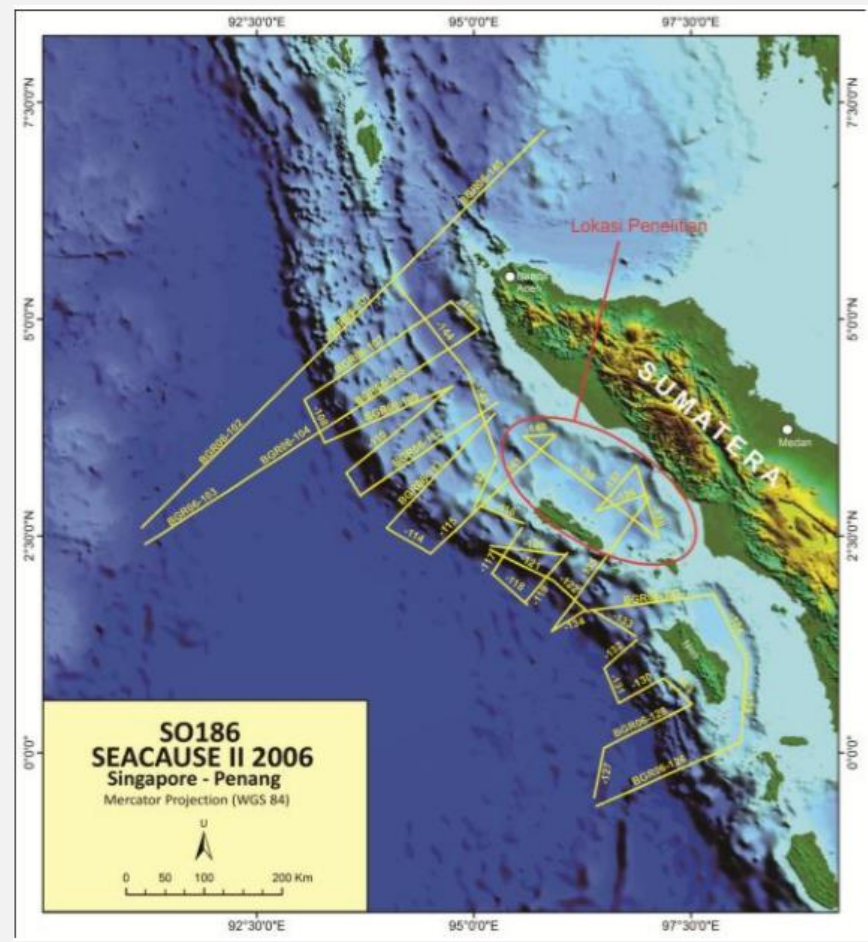

Gambar 4. Lokasi penelitian berdasarkan tatanan geologinya menempati Cekungan Busur Muka Simeulue, Sumatera (Sumber: Pengolahan data GEBCO cruise map SEACAUSE II 2006) 
Sumber data yang digunakan merupakan literatur elektronik seperti buku dan paper yang telah terbit pada suatu jurnal nasional maupun internasional, sehingga keaslian dan keakuratan data yang digunakan lebih terjamin dalam pembuatan penelitian ini. Analisis data yang dilakukan melalui studi pustaka ini adalah melalui hasil dan pembahasan dari beberapa penelitian terdahulu, sehingga didapatkan data potensi pengembangan gas hidrat di masa depan melalui aspek geologi dan geofisika.

Data yang digunakan untuk mendukung keberadaan potensi gas hidrat di perairan barat Sumatera yaitu melalui pengolahan data seismik refleksi multichannel dan interpretasi citra dari hasil survei akuisi seismik. Sedangkan di Selat Makassar, data yang digunakan yaitu data seismik 3D laut yang diambil dengan arah utara - selatan di daerah Selat Makassar dan hasil analisis AVO. Data tersebut digunakan untuk mengetahui model geometri bawah permukaan dan mengidentifikasi keberadaan gas hidrat.

\section{HASIL DAN PEMBAHASAN \\ Pembentukan Gas Hidrat}

Gas hidrat memungkinkan untuk terbentuk pada daerah yang memiliki suhu rendah dan tekanan tinggi seperti pada daerah kutub dan daerah laut (Wang \& Dongyang, 2017), seperti di permafrost dan continental margin (Gambar 5). Kondisi di wilayah permafrost (arktik) dengan kedalaman permafrost diasumsikan sekitar $600 \mathrm{~m}$ (Triarso \& Troa, 2017). Perpotongan antara gradien temperatur dengan batas fasa (phase boundary) merupakan zona stabilitias gas hidrat (GHSZ) yang dimulai pada kedalaman sekitar $200 \mathrm{~m}$ hingga kedalaman $1000 \mathrm{~m}$ (Triarso \& Troa, 2017), sedangkan sedimen diasumsikan terbentuk pada kedalaman $1200 \mathrm{~m}$. Temperatur akan mengalami penurunan bersamaan dengan bertambahnya kedalaman air laut yaitu mendekati $0^{\circ} \mathrm{C}$ pada dasar laut. Namun, pada kondisi di bawah permukaan dasar laut, temperatur terlihat mengalami peningkatan. Pada kondisi seperti ini, zona stabilitas gas hidrat (GHSZ) bagian atas berada pada kedalaman sekitar $400 \mathrm{~m}$, sedangkan bagian bawahnya berada pada kedalaman $1500 \mathrm{~m}$ dengan asumsi bahwa hidrat hanya terakumulasi pada sedimen atau tertumpuk pada permukaan dasar laut yang merupakan titik keluarnya gas metana (methane venting). Tetapi pada laut yang sangat dalam (abyssa), secara umum tidak dapat membentuk gas hidrat dalam jumlah yang besar karena tidak cukup memiliki kandungan organisme yang dibutuhkan dalam menghasilkan bahan organik yang akan terubah menjadi metana pada proses pengendapan yang cepat yang dapat mendukung pembentukan gas hidrat (Triarso \& Troa, 2017).

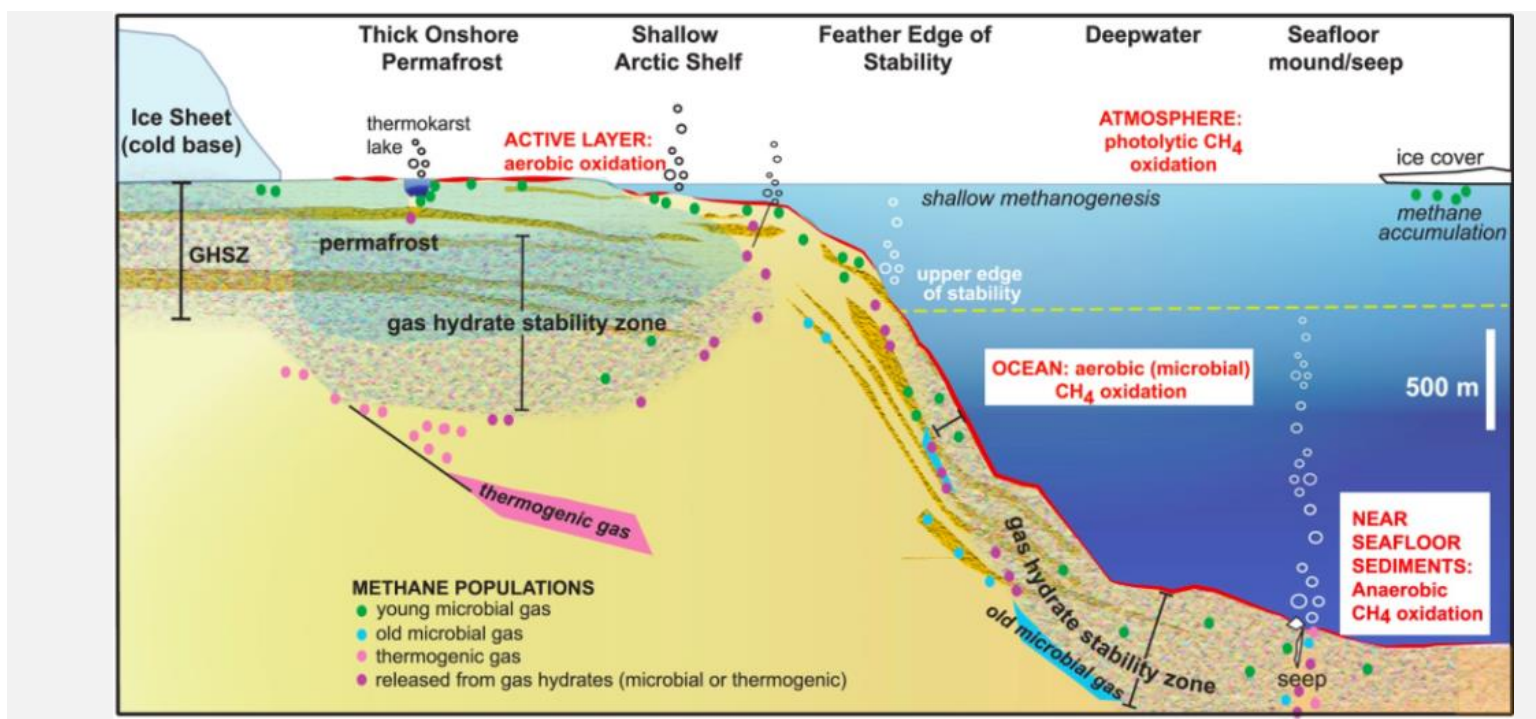

Gambar 5. Model skematik lingkungan pembentukan gas hidrat (Sumber: Ruppel \& Kessler, 2017) 
Kehadiran gas hidrat banyak ditemukan di alam seperti pada daerah arktika (kutub utara) dan juga pada sedimen laut bagian dalam dengan kombinasi faktor berupa temperatur formasi, tekanan formasi pada pori, salinitas air di pori, sifat kimia gas, ketersediaan gas dan air, jalur migrasi gas, serta kehadiran batuan reservoar merupakan unsur pembentuk gas hidrat yang sangat penting. Pada kondisi ini, kristal hidrat akan terbentuk pada kondisi dengan tekanan dan temperatur yang terbatas atau yang biasa disebut zona stabilitas gas hidrat (gas hydrate stability zone-GHSZ) (Sloan, 1990) (Gambar 6). Gas hidrat yang terbentuk pada sedimen laut biasanya terdapat di sepanjang tepi benua (continental margin) dengan tingkat pemendaman (burial rate) dari bahan organik, sehingga dapat menghasilkan gas hidrokarbon terutama metana. GHSZ membentuk gas hidrat menjadi lapisan, lembaran, butiran, mengisi pori sedimen, nodul, dan vein atau dyke pada kedalaman 100-1100 meter di bawah dasar laut, tergantung dari kondisi lokasi sekitarnya yang memiliki tekanan cukup tinggi dan suhu air yang cukup rendah dalam pembentukan gas hidrat.

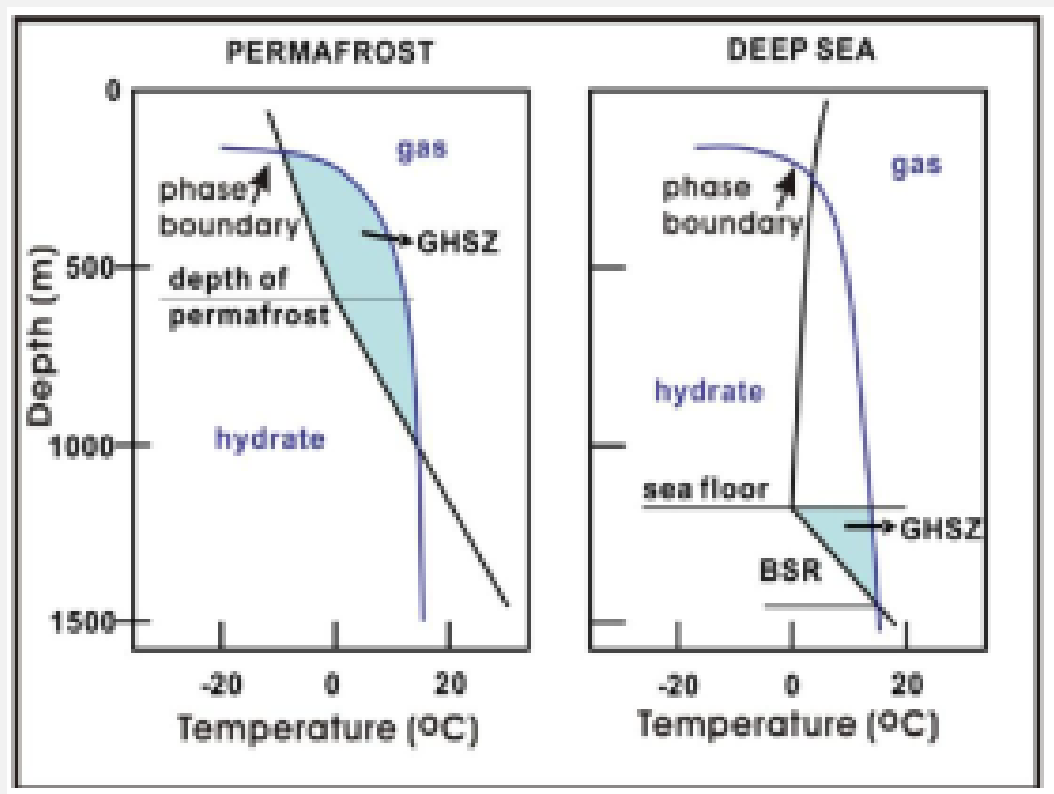

Gambar 6. Kurva stabilitas gas hidrat; hidrat stabil dalam sediment pada area yang berwarna biru muda (ditandai dengan GHSZ-gas hydrate stability zone). (Sumber: Sloan, 1990)

\section{Potensi Gas Hidrat di Indonesia}

Pada penjelasan di atas telah dijabarkan bahwa gas hidrat terbentuk pada lingkungan laut dalam (Kvenvolden dan Mcdonald, 1985; Jackson, 2004; Ruppel \& Kessler, 2017) dan lingkungan permafrost (Ruppel \& Kessler, 2017). Letak geografis Indonesia yang berada di Zona Khatulistiwa, tampalnya menyebabkan lingkungan permafrost tidak akan mungkin ditemukan di Indonesia. Maka, gas hidrat di wilayah Indonesia lebih berpotensi ditemukan di daerah lingkungan laut dalam dengan keadaan suhu rendah dan tekanan tinggi yang dimilikinya.

Selain itu, secara tektonik Indonesia terletak pada zona interaksi antar lempeng, salah satunya adalah subduksi antara Lempeng Indo-Australia dengan Lempeng Eurasia. Subduksi antar lempeng ini menyebabkan adanya wilayah laut dalam dan daerah paparan di Indonesia, sehingga mengakibatkan adanya potensi pembentukan gas hidrat di daerah tersebut. Gas tersebut dapat terbentuk karena gas metana yang dihasilkan dari kegiatan mikroba yang memakan material organik di daerah tersebut. Gas hidrat di Indonesia berada pada kedalaman yang stabil yaitu 400 hingga 600 meter di bawah permukaan laut (Ruppel \& Kessler, 2017). Keterdapatan gas hidrat sendiri sudah ditemukan di beberapa wilayah di Indonesia, seperti di 
daerah Selat Sunda (Priasmara et al., 2014) dan Selat Makassar (Jackson, 2004). Penemuan ini memberikan peluang dalam melakukan eksplorasi gas hidrat di Indonesia.

\section{Kondisi Tatanan Tektonik Selat Makassar}

Cekungan Makassar bagian utara adalah bagian dari cekungan yang berada di lepas pantai Sulawesi bagian barat. Secara tektonik daerah ini dibatasi oleh sesar Paternoster dan kompleks dari Mamuju yang dikenal sebagai sesar yang komplek dan sangat rumit (Bachrudin et al., 2015). Terkait pembentukan struktur tersebut, terdapat dua hipotesa yang dikeluarkan untuk menginterpretasikan pembentukannya. Pertama, sesar Paternoster berhubungan dengan proses kejadian bukaan (rifting) yang diikuti pemisahan (spreading) di Selat Makassar yang terbentuk pada saat Eosen, atau bahkan beberapa peneliti menginterpretasikan sebagai bagian dari suatu sistem sesar yang merupakan sebuah suture di Kalimantan (Bachrudin et al., 2015). Sedangkan hipotesa lainnya merujuk kepada adanya kolisi dari Indo-Australia terhadap Busur Banda pada waktu Pliosen (Bachrudin et al., 2015). Sedangkan Mamuju thrust series berhubungan dengan tabrakan (collision) dari mikrokontinen Banggai Sula terhadap Sulawesi pada saat Miosen tengah, dan kemungkinan diikuti oleh proses pembentukan subcekungan Bugis Pare-Pare (Bachrudin et al., 2015) dapat dilihat pada Gambar 7. Bukti ini menunjukkan bahwa pada daerah ini terjadi banyak kejadian sejarah pembentukan cekungan (poly history basins).

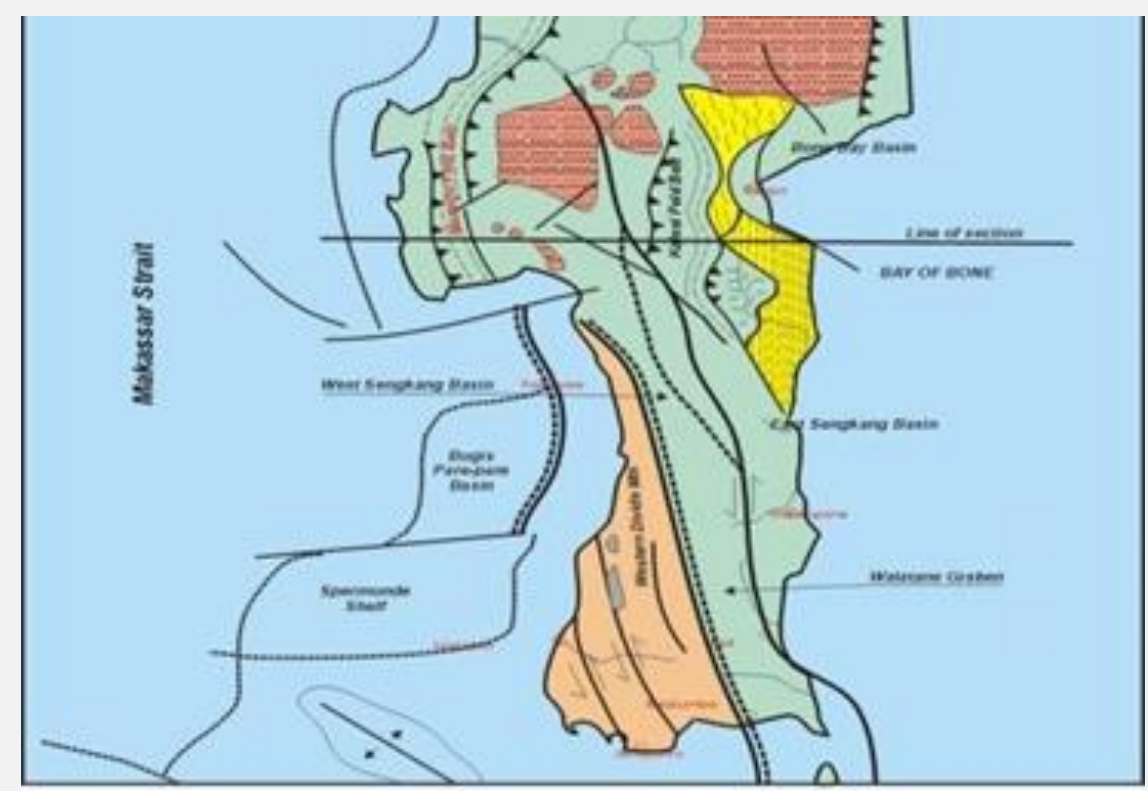

Gambar 7. Pola struktur di Cekungan Makassar Selaran. (Sumber: Bachrudin et al., 2015)

\section{Cekungan Busur Muka Simeulue, Sumatera}

Busur kepulauan Indonesia secara umum ditunjukkan oleh adanya lantai samudera (abyssal plain), palung (trench atau deformation front), prisma akresi (accretionary wedge), pematang atau tinggian busur luar (outer arc ridge/high) termasuk sesar Mentawai, cekungan busur muka (forearc basin), busur gunung api (volcanic arc) dan cekungan busur belakang (back-arc basin). Palung Sunda sendiri terbentuk disepanjang pantai barat Sumatera, menerus dari Selat Sunda ke arah utara hingga ke bagian barat Sumatera bagian utara. Kedalaman palung tersebut secara berangsur mengalami pendangkalan dari $6000 \mathrm{~m}$ menjadi $5000 \mathrm{~m}$, selain itu sumbu paritannya melebar hingga dasar palung, dan ukurannya melebar ke arah 
utara. Adapun sedimen pengisi puritan tersebut mengalami deformasi yang tergolong kecil jika dibandingkan dengan palung di sepanjang selatan Jawa.

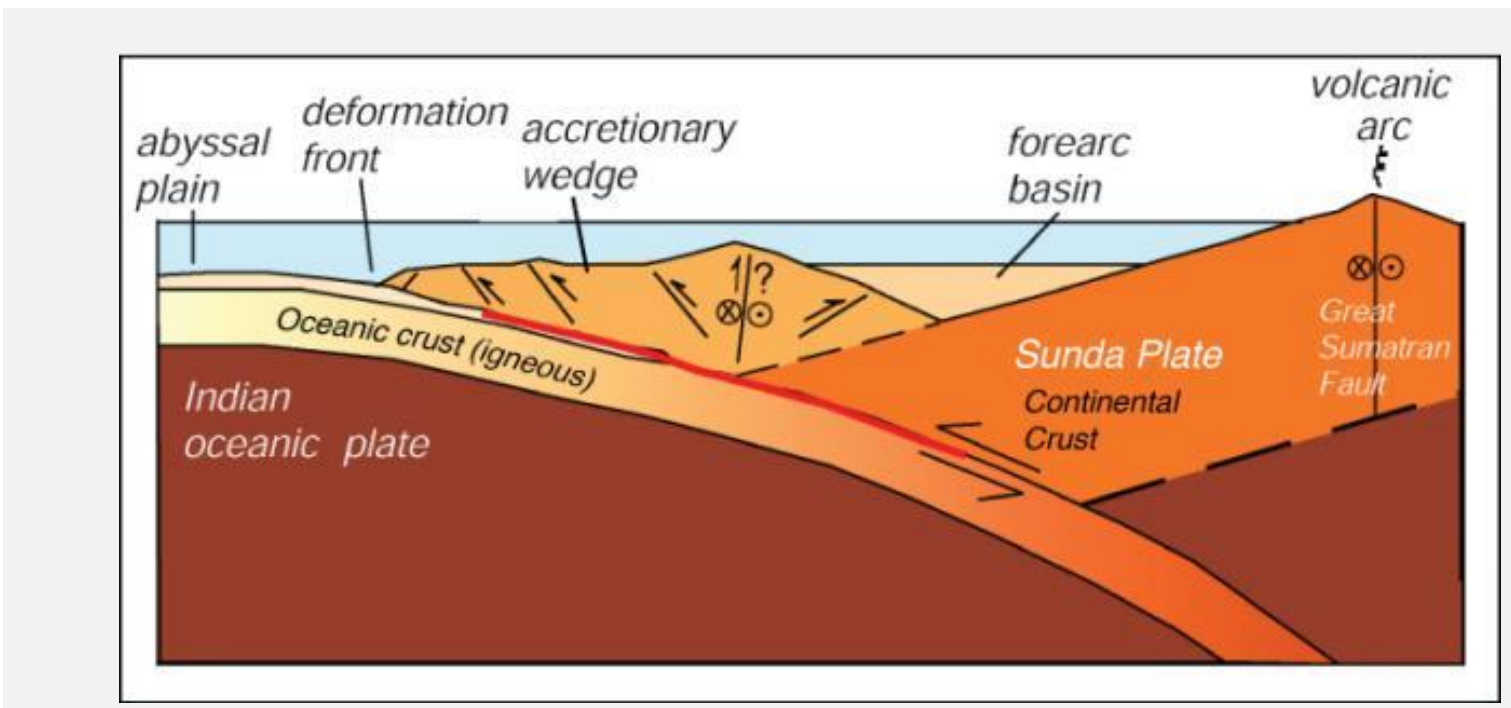

Gambar 8. Gambaran struktur geologi pada sistem subduksi Sunda. (Sumber: Triarso \& Troa, 2017)

Pada daerah antara palung laut dan busur gunung api terdapat suplai sedimen yang kompleks oleh busur tinggian bagian luar (outer arc high) yang sebagian muncul ke permukaan menjadi pulau (P. Nias, P. Siberut, P. Enggano). Di antara tinggian dan busur gunung api tersebut terdapat cekungan busur muka yang dapat terdiri dari beberapa subcekungan. Kaitannya dengan pelengkungan yang terjadi pada zona subduksi dari lempeng Indo-Australia, secara jelas terjadi pergerakan oblique di daerah Selatan Jawa dan bagian barat Selat Sunda. Daerah sumatera mempunyai dua zona sesar yang besar yaitu zona sesar mendatar Mentawai dan zona sesar mendatar Sumatera (Triarso \& Troa, 2017). Di antara kedua zona sesar tersebut, terbentuk gerakan rotasi dan ekstensi yang memicu pembentukan formasi dari Cekungan Busur Muka Simeulue. Sedimen yang mengisi cekungan ini merupakan sedimen dengan perlapisan yang sejajar dengan bagian dasar laut dan belum banyak mengalami gangguan, serta terpisah dengan beberapa struktur antiklin (Diament et al., 1992).

\section{Indikasi Gas Hidrat}

\section{Indikasi Gas Hidrat di Selat Makassar}

Analisis yang dilakukan peneliti geofisika terdahulu yaitu Jackson (2004) berada di cekungan Makassar bagian Utara, Indonesia dengan tujuan untuk mendapatkan deposit gas hidrat di daerah tersebut. Berdasarkan analisis tersebut ditemukan bahwa indikasi adanya deposit gas hidrat berada di utara selat Makassar, di antara Pulau Sulawesi dan Kalimantan. Penelitian dilakukan dengan menggunakan metode geofisika, yaitu metode BSR (Bottom Stimulating reflector) yang diinterpretasi dari penampang multi-client 2D seismik (Gambar 9).

Data seismik tersebut didapatkan melalui pengukuran yang dilakukan pada wilayah seluas $100.000 \mathrm{~km}^{2}$, kemudian dengan menggunakan BSR secara spesifik didapatkan area seluas $21.000 \mathrm{~km}^{2}$ (Bachrudin et al., 2015). BSR sendiri dapat mengidentifikasi area seluas $8.000 \mathrm{~km}^{2}$ pada foldbelt di kedalaman lautan Sulawesi Barat (Bachrudin et al., 2015). Asal endapan atau sedimen yang ditemukan di daerah foldbelt Sulawesi bagian barat berasal dari Mahakam delta yang berumur Pliosen akhir. Peristiwa tektonik yang ada berpengaruh terhadap awal mula terbentuknya west-verging fault propagation fold yang membentuk foldbelt. Foldbelt tersebut terdiri dari sejumlah thurst sheets yang membentuk struktur anticlinal panjang dan menginisiasi terbentuknya cekungan kecil (mini-basin) seperti Gambar 9. 


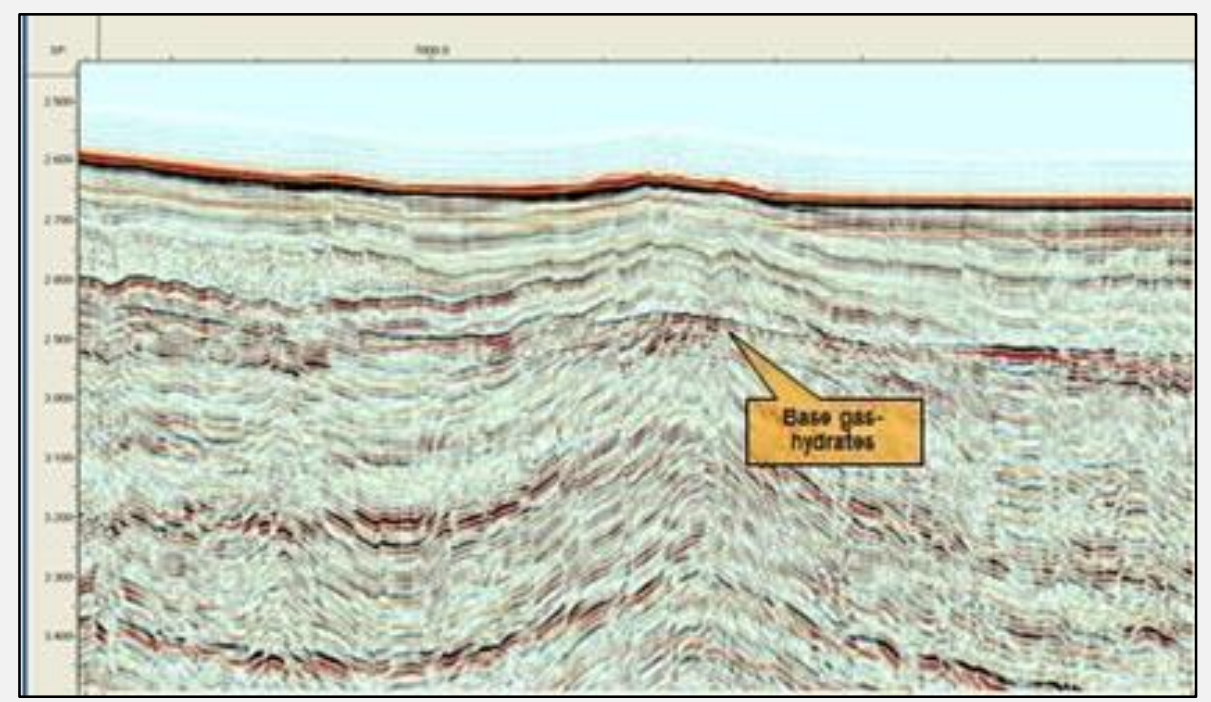

Gambar 9. Base Gas hidrate pada cekungan Makassar. (Sumber: Bachrudin et al., 2015)

Proses pengendapan yang terjadi merupakan rangkaian proses turbidit "spill and fill, sehingga memberikan efek yang signifikan terhadap proses akumulasi gas hidrat di daerah foldbelt Sulawesi bagian Barat. Aliran turbidit dapat membawa material organik (terriginous) yang berasal dari daratan sebagai sumber material organik, selanjutnya bakteri akan memproduksi gas metana di kedalaman laut yang biasa disebut dengan proses pembentukan gas biogenik), nantinya gas metana yang dihasilkan tersebut akan dibutuhkan dalam proses pembentukan gas hidrat (Jackson, 2004).

Untuk membuktikan dan memperkuat interpretasi bahwa di daerah tersebut terdapat gas hidrat, dapat dilakukan dengan menggunakan analisa AVO melalui metode Far Stack-Near Stack. Dari hasil metode Far Stack - Near Stack, maka diperoleh hasil berupa nilai negatif dan jika dihubungkan dengan analisis AVO maka diperoleh AVO kelas III. Hasil AVO kelas III menggambarkan bahwa adanya potensi keberadaan gas hidrat pada daerah tersebut. Hasil analisis AVO dengan metode Far Stack - Near Stack dapat dilihat pada Gambar 10 dan identifikasi keberadaan gas hidrat dapat dilihat pada Gambar 11.

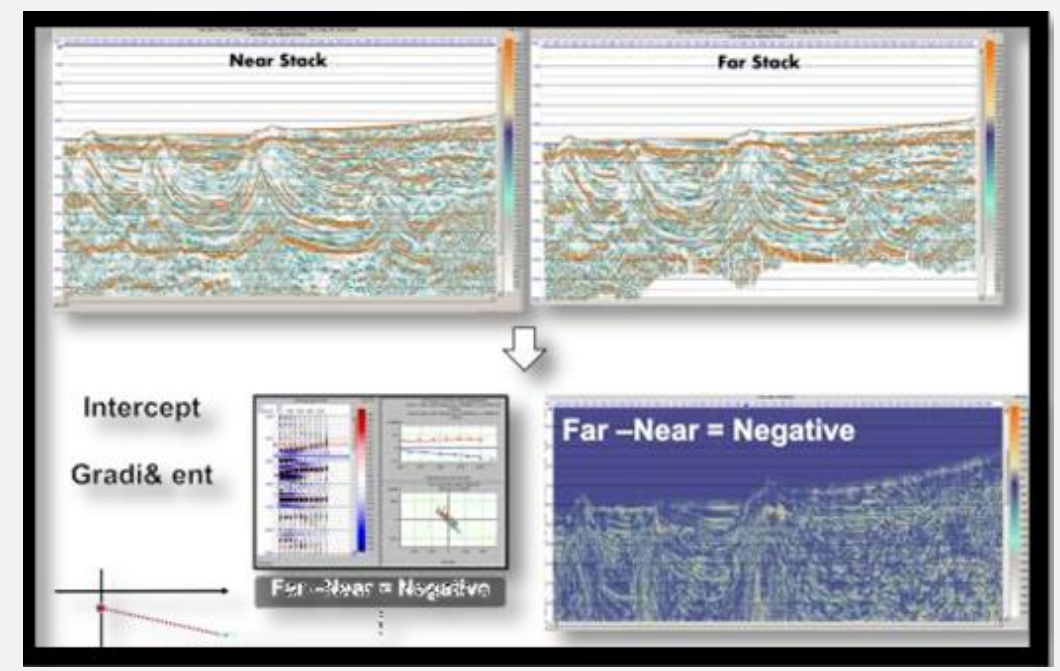

Gambar 10. Analisis AVO dengan Metode Far Stack - Near Stack untuk menentukan keberadaan gas hidrat. (Sumber: Bachrudin et al., 2015) 


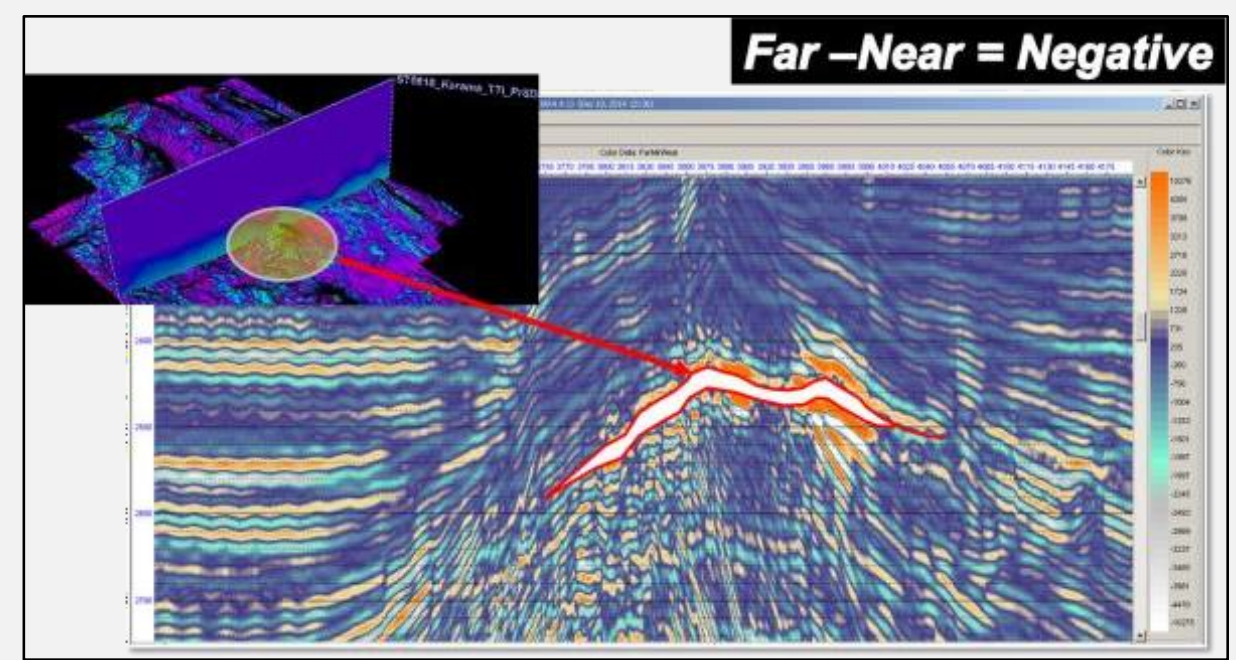

Gambar 11. Identifikasi keberadaan gas hidrat menggunakan metode Far Stack - Near Stack. (Sumber: Bachrudin et al., 2015)

\section{Indikasi Gas Hidrat di Cekungan Busur Muka Simeulue, Sumatera}

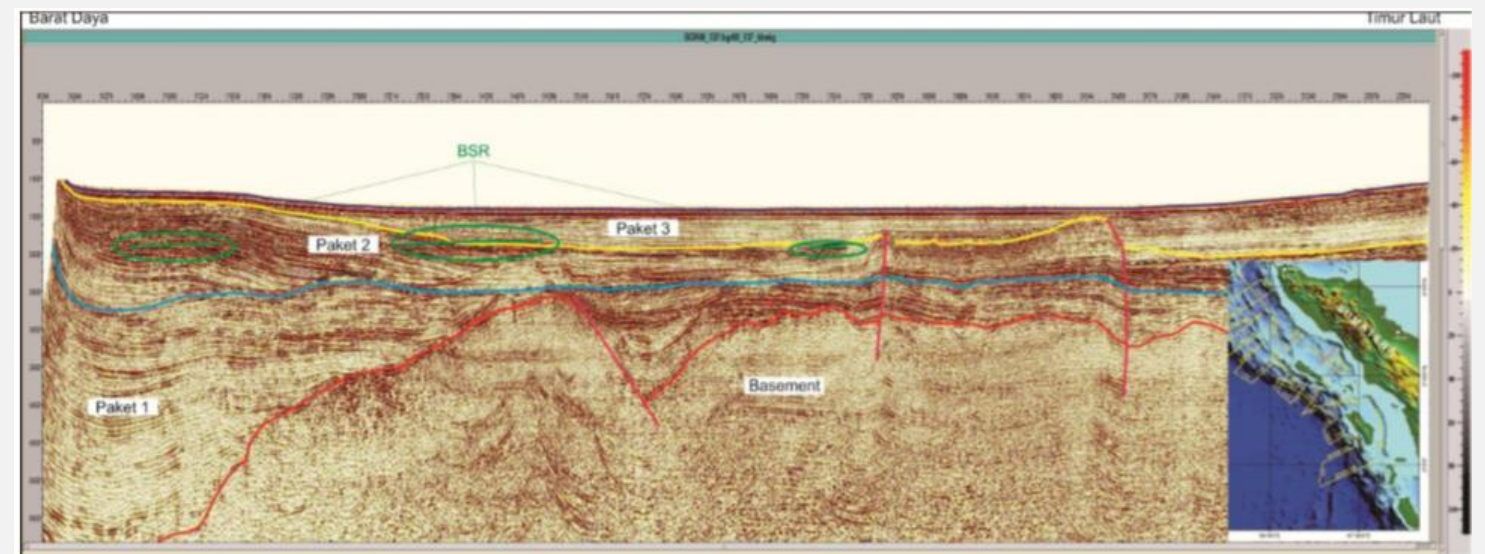

Gambar 12. Penampang seismik hasil dari interpretasi yang memperlihatkan kondisi basement, sedimen, BSR dan tektonik. (Sumber: Triarso \& Troa, 2017)

\section{Basement}

Basement atau batuan dasar daerah penelitian, diinterpretasikan sebagai batuan dengan permukaan kasar sebagai akibat dari perlipatan dan pengangkatan batuan yang diikuti oleh proses erosi regional terhadap batuan tersebut. Selanjutnya, terdapat struktur tarikan yang membentuk half graben (pada bagian tengah penampang) dan penurunan membentuk Cekungan Busur Muka Simeulue dengan arah tenggara - barat laut sejajar dengan Palung Sunda atau pola umum struktur geologi kawasan Sumatera bagian utara.

\section{Sedimen}

Penampang lintasan seismik tersebut diinterpretasikan memiliki tiga paket sedimen dengan pengendapan yang berbeda, proses erosi, dan sesar. Paket satu diinterpretasikan sebagai pengendapan sedimen yang secara tidak selaras atau secara syndepositional menutupi batuan dasar baik berasal dari daratan Sumatera maupun dari laut terbuka. Sementara itu, penurunan cekungan terus berlangsung salah satunya melalui Sesar 1, sehingga menghasilkan 
endapan sedimen yang tebal (3.250 milidetik) yang pada bagian barat dayanya kemungkinan mulai terangkat. Sementara itu, Sesar 1 (sesar normal) masih terus aktif bersamaan dengan pengendapan sedimen Paket 2 dengan tebal 375 - 1.250 milidetik yang diendapkan selaras di atas horison berwarna biru terang yang dominan berasal dari arah barat daya kemungkinan terkait dengan pengangkatan busur muka atau pembentukan prisma akresi. Pasangan sesar wrench atau sesar mendatar (Sesar 2 dan 3) berkembang bersamaan dengan pengendapan sedimen Paket 2. Fosil terumbu teramati tumbuh (carbonate build up) secara terbatas di tepian tebing half graben yang terus bergerak turun akibat gaya tarikan. Pengangkatan busur muka terus berlangsung melalui sistem prisma akresi kemudian secara toplap diendapkan sedimen pada bagian atasnya. Pada sedimen Paket 3 diendapkan menutupi seluruh kawasan Cekungan Busur Muka Simeulue.

\section{Bottom Simulating Reflector (BSR)}

Pada penampang seismik tersebut, BSR atau Bottom Simulating Reflector teramati di bagian tengah Cekungan Simeulue hingga ke barat daya. BSR membentuk lensa menyempit pada kedua ujungnya. Selain itu, BSR yang terletak pada bagian tengah terlihat hampir sejajar dengan horison sedimen di sekitarnya tetapi pada bagian barat daya terlihat memotong horison sedimen. Sedangkan, pada arah barat laut atau tepi cekungan bagian timur (ke arah darat Pulau Sumatera) BSR tidak tampak, hal ini diperkirakan bahwa ke arah tepi cekungan tidak terbentuk zona stabilitas gas hidrat yang memungkinkan terjadinya gas hidrat dan hal yang kedua adalah gas hidrat sebenarnya hadir tetapi tidak teridentifikasi akibat posisi terakumulasinya sejajar dengan perlapisan sedimen yang ada.

\section{KESIMPULAN}

Indikasi adanya potensi gas hidrat di wilayah Indonesia dapat ditemukan di beberapa daerah yaitu Selat Makassar dan Cekungan Busur Muka Simeulue, Sumatera. Hal ini dibuktikan melalui pengukuran dengan metode geofisika seismik dan karakteristik BSR (Bottom Stimulating reflector), serta analisis AVO jika diperlukan untuk memperkuat intrepretasi adanya gas hidrat di daerah tersebut. Potensi gas hidrat khususnya di Indonesia biasanya ditemukan di daerah dengan lingkungan laut dalam yang didukung oleh kondisi tektonik yang terjadi di Indonesia. Aktivitas tektonik di Indonesia seperti subduksi juga merupakan hal yang mendukung terbentuknya gas hidrat. Seperti di Selat Makassar terdapat struktur berupa sesar naik, sedangkan di Cekungan Busur Muka Simeulue, Sumatera terdapat sesar normal, struktur ini merupakan hasil dari aktivitas tektonik tersebut, yang berguna untuk membantu aktivitas pembentukan gas hidrat. Terkait pengembangan sumber energi baru untuk masa depan, maka dibutuhkan riset dan eksplorasi yang mulai diarahkan ke daerah laut dalam, terutama untuk menindaklanjuti adanya temuan indikasi gas hidrat yang berada di wilayah Cekungan Busur Muka Simeulue, Sumatera dan Selat Makassar karena potensinya sebagai sumber energi baru yang dapat menjadi alternatif bagi pemenuhan kebutuhan energi di masa depan.

\section{UCAPAN TERIMA KASIH}

Terima kasih kami sampaikan kepada seluruh lembaga dan pihak terkait yang telah mendukung penulisan paper ini. Kegiatan ini telah menghasilkan data dan keadaan terkini dari potensi gas hidrat yang melimpah di wilayah maritim Indonesia sebagai sumber energi nonkonvensional masa depan. Terima kasih kami sampaikan juga kepada Dosen Teknik Geologi Universitas Pembangunan Nasional "Veteran" Yogyakarta dan rekan-rekan Pangea 2018 atas bimbingan dan bantuannya dalam penulisan karya tulis ilmiah ini.

\section{DAFTAR PUSTAKA}

Bachrudin, A., Firmansyah, Y., \& Sunardi, E. (2015). Studi Awal Identifikasi Gas Hidrat Menggunakan Metode Seismik di Lapangan YF, Selat Makassar. Seminar Nasional ke-II FTG Universitas Padjajaran. 
Dagar, S. \& Joshi, A. (2013). Gas Hydrates - A New Horizon. 10th Biennial International Conference \& Exposition. Dhanbad (Jharkhand), India.

Davie, M. K., Zatsepina, O. Y., \& Buffett, B. A. (2004). Methane solubility in marine hydrate environments. Marine Geology, 203(1), 177-184. [CrossRef]

Diament, M., Harjono, H., Karta, K., Deplus, C., Dahrin, D., Zen, M.T., Gerard, Jr., M., Lassal, O., Martin, A., \& Jamold, J. (1992). Mentawai fault zone off Sumatra a new key to the geodynamics of western Indonesia. Geology, 20(3), 259-262. [CrossReff]

Fraser, T.H., Jackson, B.A., Barber, P.M., Baillie, P., \& Myers, K., (2003). The West Sulawesi Fold Belt and Other New Plays Within the North Makassar Straits - A Prospectivity Review. Proceedings Indonesian Petroleum Association, 29th Annual Convention. Jakarta, Indonesia.

Guntoro, A. (1999). The formation of the Makassar Strait and the separation between SE Kalimantan and SW Sulawesi. Journal of Asian Earth Sciences, 17(1-2), 79 - 98. [CrossRef]

Hall, R., (2012). Sundaland and Wallacea: geology, plate tectonics and paleogeography. Cambridge Univesity Press, Cambridge.

Jackson, B.A., (2004). Seismic evidence for gas hydrates in the North Makassar Basin, Indonesia. Petroleum Geoscience, 10(3), 227-238. [CrossRef]

Katz, D.L., Cornell, D., Kobayashi, R., Poetmann, F.H., Vary, J.H., Elenblass, J.R., \& Weinaug, C.F. (1959). Handbook of Natural Gas Engineering. McGrawHill, New York.

Kvenvolden, K. A., \& McDonald, T. J., (1985). Gas hydrates of the Middle America TrenchDSDP/IPOD Leg 84, In Initial Reports of Deep Sea Drilling Project, Vol. 84 (R. von Huene, J. Aubouin, et a1., eds.), U.S. Government Printing Office, Washington, D.C., pp. 667-682.

Kvenvolden, K.A. (1988). Methane Hydrate: A Major Reservoir of Carbon in The Shallow Geosphere. Chemical Geology, 71(1-3), 41-51. [CrossRef]

Lin, C.-C., Tien-Shun Lin, A., Liu, C.-S., Chen, G.-Y., Liao, W.-Z., \& Schnurle, P. (2009). Geological controls on BSR occurrences in the incipient arc-continent collision zone off southwest Taiwan. Marine and Petroleum Geology, 26(7), 1118- 1131. [CrossRef]

Makogon, Y. F., Holditch, S. A., \& Makogon, T. Y. (2007). Natural gashydrates-A potential energy source for the 21st Century. Journal of Petroleum Science and Engineering, 56(1), 14-31. [CrossRef]

Max, M.D., \& Johnson A.H. (2016). Exploration and Production of Oceanic Natural Gas Hydrate. Springer, Switzerland.

Priasmara, F.N.D., Aryono, A.F., Barus, F.I., \& Sijabat, R.F., (2014). Indonesia Gas Hydrate Potential of Sunda Strait Case Study: Future Energy or Geohazard. Proceedings. Indon. Petrol. Assoc., 38th Ann. Conv, Jakarta.

Ruppel, C.D., \& Kessler, J.D., (2017). The interaction of climate change and methane hydrates. Rev. Geophys, 55(1), 126-168. [CrossRef]

SKKMIGAS. (2020, September 07). Cadangan Energi Indonesia. www.skkmigas.go.id. 
Sloan, E.D. (1990). Clathrate hydrates of natural gases. Maracel Bekker Inc., New York.

Triarso, E., Troa, R.A. (2017). Indikasi Keberadaan Gas Hidrat pada Cekungan Busur Muka Simeulue Dan Potensinya Sebagai Sumber Energi Masa Depan. Jurnal Kelautan Nasional, 11(3), 127-140. [CrossRef]

Wang, X. \& Dongyan, P. (2017) Application of AVO attribute Inversion technology to gas hydrate identification in the Shenhu Area, South China Sea. Marine and Petroleum Geology, Elseivier, 80, 23-31. [CrossRef]

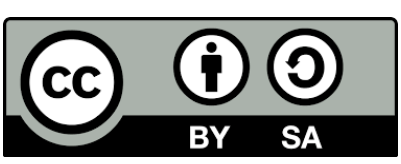

Copyright (c) 2021 by the authors. This work is licensed under a Creative Commons Attribution-ShareAlike 4.0 International License. 